Article

\title{
Study on the Synthesis of ZnO Nanoparticles Using Azadirachta indica Extracts for the Fabrication of a Gas Sensor
}

\author{
Tirtha Raj Acharya ${ }^{1,2}$, Pradeep Lamichhane ${ }^{1}\left(\mathbb{D}\right.$, Rizwan Wahab ${ }^{3}{ }^{(0)}$, Dinesh Kumar Chaudhary ${ }^{4}(\mathbb{D}$, \\ Bhanu Shrestha ${ }^{5}{ }^{\circ}$, Leela Pradhan Joshi ${ }^{4}\left[\right.$, Nagendra Kumar Kaushik $1, * \mathbb{1}$ and Eun Ha Choi ${ }^{1, *}$
}

\section{check for} updates

Citation: Acharya, T.R.; Lamichhane, P.; Wahab, R.; Chaudhary, D.K.;

Shrestha, B.; Joshi, L.P.; Kaushik, N.K.; Choi, E.H. Study on the Synthesis of ZnO Nanoparticles Using Azadirachta indica Extracts for the Fabrication of a Gas Sensor. Molecules 2021, 26, 7685. https://doi.org/10.3390/ molecules26247685

Academic Editor: Mariana Emilia Ghica

Received: 26 November 2021 Accepted: 17 December 2021 Published: 19 December 2021

Publisher's Note: MDPI stays neutral with regard to jurisdictional claims in published maps and institutional affiliations.

Copyright: (c) 2021 by the authors. Licensee MDPI, Basel, Switzerland. This article is an open access article distributed under the terms and conditions of the Creative Commons Attribution (CC BY) license (https:/ / creativecommons.org/licenses/by/ $4.0 /)$.
1 Plasma Bioscience Research Center, Applied Plasma Medicine Center, Department of Electrical and Biological Physics, Kwangwoon University, Seoul 01897, Korea; tirtharajacharya2050@gmail.com (T.R.A.); theprodip@gmail.com (P.L.)

2 Department of Physics, Saint Xavier's College, Tribhuvan University, Maitighar, Kathmandu 44600, Nepal

3 Chair for DNA Research, Department of Zoology, College of Science, King Saud University, Riyadh 11451, Saudi Arabia; rwahab@ksu.edu.sa

4 Department of Physics, Amrit Campus, Tribhuvan University, Kathmandu 44600, Nepal; din.2033@gmail.com (D.K.C.); leela.pradhan@gmail.com (L.P.J.)

5 Department of Electronic Engineering, Kwangwoon University, Seoul 01897, Korea; bnu@kw.ac.kr

* Correspondence: kaushik.nagendra@kw.ac.kr (N.K.K.); ehchoi@kw.ac.kr (E.H.C.)

Abstract: This paper compared the effects of $A$. indica plant proteins over chemical methods in the morphology of zinc oxide nanoparticles ( $\mathrm{ZnO}$ NPs) prepared by a co-precipitation method, and ethanol sensing performance of prepared thin films deposited over a fluorene-doped tin oxide (FTO) bind glass substrate using spray pyrolysis technique. The average crystallite sizes and diameters of the grain-sized cluster ZnO NPs were 25 and (701.79 \pm 176.21$) \mathrm{nm}$ for an undoped sample and 20 and $(489.99 \pm 112.96) \mathrm{nm}$ for $A$. india dye-doped sample. The fourier transform infrared spectroscopy (FTIR) analysis confirmed the formation of the $\mathrm{Zn}-\mathrm{O}$ bond at $450 \mathrm{~cm}^{-1}$, and also showed the presence of plant proteins due to $A$. indica dye extracts. ZnO NPs films exhibited good response (up to 51 and $72 \%$ for without and with $A$. indica dye-doped extracts, respectively) toward ethanol vapors with quick response-recovery characteristics at a temperature of $250{ }^{\circ} \mathrm{C}$ for undoped and $225^{\circ} \mathrm{C}$ for A. indica dye-doped $\mathrm{ZnO}$ thin films. The interaction of $A$. indica dye extracts helps to decrease the operating temperature and increased the response and recovery rates of the sensor, which may be due to an increase in the specific surface area, resulting in adsorption of more oxygen and hence high response results.

Keywords: ZnO nanoparticles; Azadirachta indica; functional group; thin film; ethanol sensor; sensitivity; response and recovery rates

\section{Introduction}

Gas tracking devices are becoming increasingly popular for a variety of physical, chemical, and biological purposes. For the detection of harmful pollutant gases, flammable gases, and organic vapors, metal oxide-based chemical sensors have been widely used. Chemical sensors have several benefits, including low cost, compact size, great sensitivity, and minimal power usage [1]. Ethanol is one of the most widely used and distributed alcohols in the fields of food technology, brewing, medicine, clinical research, and biotechnology [2-5]. Excessive ethanol consumption is harmful to living creatures. In humans, ethanol vapor exposure during development can result in ventricular and septal wall thickening [2]. As a result, detecting ethanol fumes is quite important at this time. Different metal oxide semiconductor (MOSs) such as $\mathrm{ZnO}, \mathrm{TiO}_{2}, \mathrm{WO}_{3}, \mathrm{In}_{2} \mathrm{O}_{3}, \mathrm{MoO}_{3}, \mathrm{SnO}_{2}$, and $\mathrm{Fe}_{2} \mathrm{O}_{3}$, and multi-component oxides, such as $\mathrm{BiFeO}_{3}, \mathrm{Al}_{2} \mathrm{O}_{3}-\mathrm{ZnO}, \mathrm{Cu}-\mathrm{TiO}_{2}, \mathrm{Cr}_{-} \mathrm{TiO}_{3}$, $\mathrm{MgAl}_{2} \mathrm{O}_{4}, \mathrm{SnO}_{2}-\mathrm{Pd}-\mathrm{Pt}, \mathrm{SrTiO}_{3}$, and $\mathrm{Nb}_{2} \mathrm{O}_{5}-\mathrm{ZnO}$, are useful for UV sensing [6-8], solar cells [9], photocatalytic effects [10], and gas sensing applications [11]. Gas sensors based on the nanostructures of MOSs have a high sensitivity with short response and recovery 
times [12]. In addition to the chemical properties of MOSs, the surface morphology and surface-to-volume ratio also affect the relative change in resistance of MOS gas sensors [13].

Zinc oxide $(\mathrm{ZnO})$ is a set II-VI $n$-type semiconductor with a vast band gap $(3.3 \mathrm{eV})$ and exceptional assets, such as high exciton binding energy (60 MeV) [14], transparency in the visible region and strong infrared reflectivity [15], excellent audio characteristics and outstanding electronic chattels [16], high electron mobility $\left(100 \mathrm{~cm}^{2} \mathrm{v}^{-1} \mathrm{~s}^{-1}\right)$ [17], strong room-temperature luminescence, high chemical and thermal stability, abundance in nature, and environmental friendliness [18]. This unique property makes $\mathrm{ZnO}$ a proficient semiconducting material in gas sensors. The biological production of ZnO NPs utilizing plant extracts, such as leaves, roots, flowers, and seeds as a bio template, is of particular interest to researchers [12]. This green technique has various advantages, including environmentally friendliness, shorter time, lower-cost precursors, and a higher-purity result; the handling procedure is easy and does not require expensive equipment [13]. Many studies have been conducted on the green synthesis of ZnO NPs by plant leaves such as Ixora Coccinea, Artocarpus gomezianus, Coptidis rhizoma, Citrus aurantifolia, Zingiber officinalis, Cyanometraramiflora, $A$. indica, and others $[19,20]$. However, only a few studies on the natural synthesis of $\mathrm{ZnO}$ NPs using dye extracts from $A$. indica have been conducted. It is reported that the $A$. indica extracts contain approximately 140 chemical compounds [21]. The main composition of $A$. indica leaf includes crude protein (12.40-18.27\%), crude fiber (11.40-23.08\%), $\mathrm{N}$ free extract (43.32-66.60\%), ether extract (2.27-6.24\%), total ash (7.75-18.37\%), calcium (0.89-3.96\%), and phosphorus (0.10-0.30\%) [22]. Incubation of benzoquinones obtained from $A$. indica leaves promoted activation of quinones, which helped to reduce particle size, according to Mathew et al. [14]. Nicole et al. reported that proteins of both high and low molecular weight play a key role in the both stability and reduction of green produced ZnO NPs [15]. Phytochemicals such as flavones, polyols, terpenoids, and plant proteins found in the $A$. indica leaf contribute functional groups of amines, alcohols, ketones, aldehydes, and carboxylic acid in bio-reduction reactions [16]. Metal compounds are converted to ZnO NPs by phytochemicals and enzymes found in the $A$. indica plant [15]. These metabolites from the $A$. indica leaf have reducing characteristics, allowing zinc ions to be quickly reduced to $\mathrm{ZnO}$ NPs.

The interaction of analyte gas molecules with deposited oxygen ions $\left(\mathrm{O}_{2}{ }^{-}\right.$or $\left.\mathrm{O}^{-}\right)$on the MOS gas sensors determines its sensing capability, and the surface shape plays a crucial role in oxygen ion adsorption [5]. The addition of $A$. indica plant dye extracts changed the surface shape and enhanced the stability of ZnO NPs. This morphological impact in $\mathrm{ZnO}$ NPs is beneficial to gas sensing. A novel idea proposed in this study is the utilization of plant dye extracts in $\mathrm{ZnO}$ thin films for the manufacture of an ethanol gas sensor. The current research examines how $A$. indica dye extract is used to generate and analyze $\mathrm{ZnO}$ NPs as well as how it functions as a vapor detector.

\section{Results and Discussion}

\subsection{Structural Analysis}

The structural analysis of the prepared ZnO NPs with and without $A$. indica dye extracts was performed using X-ray diffraction (XRD). XRD testing was performed using a $\mathrm{D}_{2}$ Phaser (Bruker, Berlin, Germany) diffractometer with $\mathrm{CuK}_{\alpha}$ radiation (wavelength $=1.54184 \AA$ ) at an operating voltage of $30 \mathrm{kV}$ and a current of $10 \mathrm{~mA}$. The scanning rate was 0.33 degrees per second in the $2 \theta$ range of $20^{\circ}$ to $80^{\circ}$. Figure 1 shows the XRD pattern of the asprepared ZnO NPs. The sharp diffraction peak indicates the good crystallinity of the prepared $\mathrm{ZnO}$ NPs [23]. Interplanar spacing (d-spacing) was obtained using Bragg's relation: $2 d \sin \theta=n \lambda$ [17], where $\lambda$ is the $X$-ray wavelength, $n$ is the order of reflection, and $\theta$ is Bragg's angle. The calculated values of ' $\mathrm{d}$ ' are compared with the standard JCPDS values for indexing the (hkl) planes as demonstrated in Table 1 [24]. There were slight shifts in the $2 \theta$ values with those of the JCPDS card number 36-1451. This may be due to the strain. The comparison of the ' $\mathrm{d}$ ' values of both samples shows only a slight decrease in ' $d$ ' values, which may be due to the doping of the parent solution with A. indica dye [25]. 


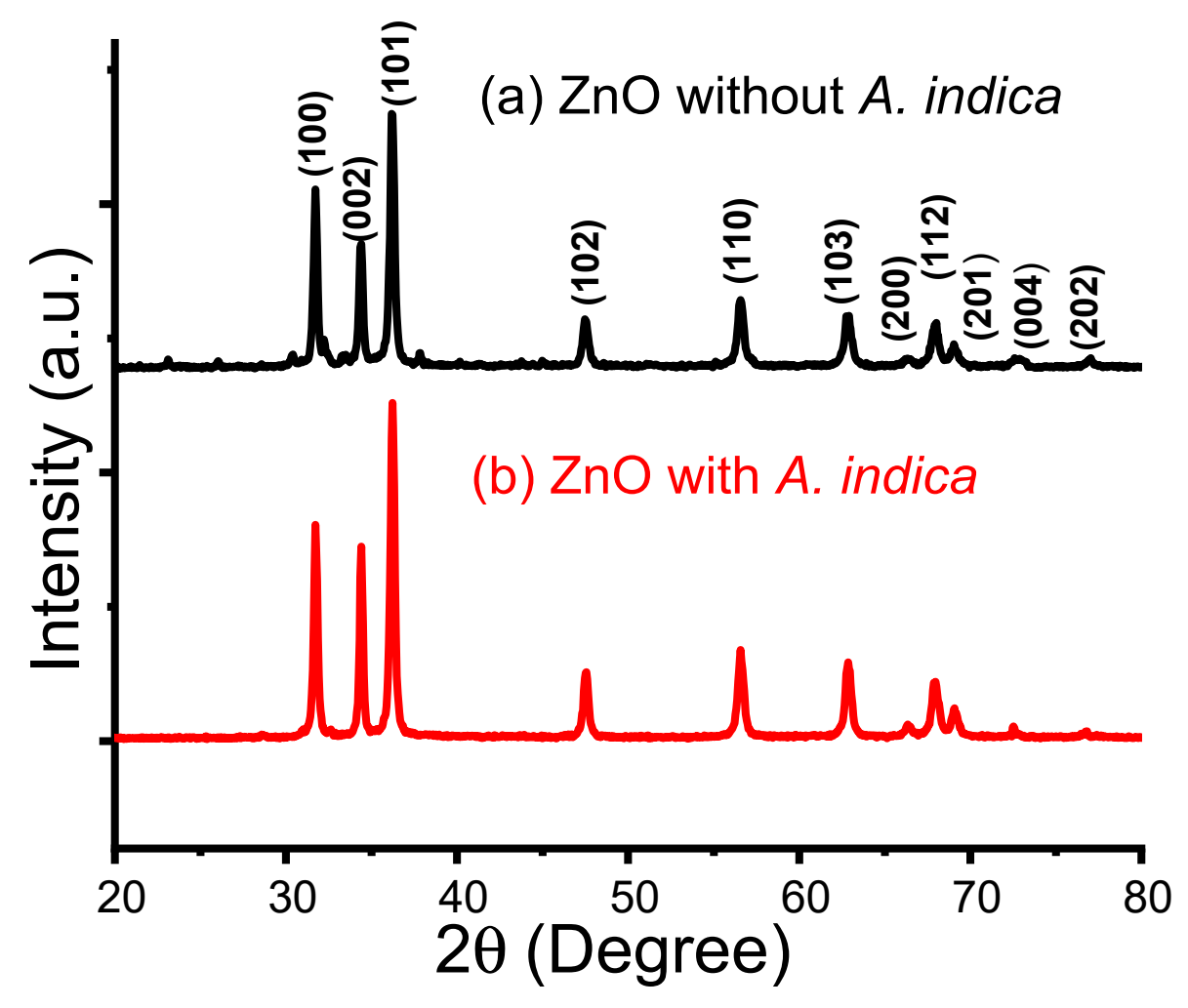

Figure 1. X-ray diffraction pattern of ZnO NPs prepared (a) without plant dye extracts and (b) with A. indica dye extracts.

Table 1. Calculation of d-spacing and crystallite size of prepared ZnO NPs.

\begin{tabular}{|c|c|c|c|c|c|c|}
\hline Sample & $\begin{array}{l}\text { Plane } \\
\text { (hkl) }\end{array}$ & $2 \theta$ (Degree) & FWHM ( $\beta)$ & $\begin{array}{c}\mathrm{d}(\mathrm{nm}) \\
\text { (Observed) }\end{array}$ & $\begin{array}{c}\mathrm{d}(\mathrm{nm}) \\
\text { (JCPDS) }\end{array}$ & $\begin{array}{c}\text { Average D } \\
\text { (nm) }\end{array}$ \\
\hline \multirow{11}{*}{$\begin{array}{c}\text { ZnO NPs } \\
\text { Without dye } \\
\text { extracts }\end{array}$} & $(100)$ & 31.7279 & 0.2887 & 0.2817 & 0.2814 & \multirow{11}{*}{$25 \mathrm{~nm}$} \\
\hline & $(002)$ & 34.3859 & 0.2932 & 0.2605 & 0.2603 & \\
\hline & (101) & 36.2159 & 0.3331 & 0.2478 & 0.2475 & \\
\hline & (102) & 47.5432 & 0.4110 & 0.1911 & 0.1911 & \\
\hline & (110) & 56.5770 & 0.4579 & 0.1625 & 0.1624 & \\
\hline & (103) & 62.8518 & 0.5127 & 0.1477 & 0.1477 & \\
\hline & (200) & 66.1982 & 0.3328 & 0.1410 & 0.1407 & \\
\hline & (112) & 67.8183 & 0.4489 & 0.1380 & 0.1378 & \\
\hline & (201) & 69.0333 & 0.4476 & 0.1359 & 0.1358 & \\
\hline & $(004)$ & 72.5773 & 0.3236 & 0.1301 & 0.1301 & \\
\hline & (202) & 77.0325 & 0.3832 & 0.1236 & 0.1238 & \\
\hline Sample & $\begin{array}{c}\text { Plane } \\
\text { (hkl) }\end{array}$ & $2 \theta$ (degree) & FWHM ( $\beta)$ & $\begin{array}{c}\mathrm{d}(\mathrm{nm}) \\
\text { (Observed) }\end{array}$ & $\begin{array}{c}\mathrm{d}(\mathrm{nm}) \\
\text { (JCPDS) }\end{array}$ & $\begin{array}{c}\text { Average D } \\
(\mathrm{nm})\end{array}$ \\
\hline \multirow{11}{*}{$\begin{array}{l}\mathrm{ZnO} \text { NPs with } \\
\text { A. indica dye } \\
\text { extracts }\end{array}$} & $(100)$ & 31.6753 & 0.3976 & 0.2823 & 0.2814 & \multirow{11}{*}{$20 \mathrm{~nm}$} \\
\hline & (002) & 34.3385 & 0.2745 & 0.2609 & 0.2603 & \\
\hline & (101) & 36.1626 & 0.3991 & 0.2482 & 0.2475 & \\
\hline & (102) & 47.4574 & 0.3885 & 0.1914 & 0.1911 & \\
\hline & (110) & 56.4965 & 0.3885 & 0.1627 & 0.1624 & \\
\hline & (103) & 62.7772 & 0.4705 & 0.1478 & 0.1477 & \\
\hline & (200) & 66.1345 & 0.4451 & 0.1411 & 0.1407 & \\
\hline & (112) & 67.8529 & 0.5553 & 0.1380 & 0.1378 & \\
\hline & (201) & 69.1237 & 0.5764 & 0.1357 & 0.1358 & \\
\hline & (004) & 72.4312 & 0.6522 & 0.1303 & 0.1301 & \\
\hline & (202) & 77.1056 & 0.6822 & 0.1235 & 0.1238 & \\
\hline
\end{tabular}


The average crystallite size was estimated by measuring the broadening of the $X$ ray diffraction peaks observed in the XRD pattern using the Debye-Scherrer formula: $D=\frac{0.9 \lambda}{\beta \cos \theta}$ [26], where 0.9 is the Debye constant, $\lambda$ is the X-ray wavelength of $1.54184 \AA$, and $\beta$ is the FWHM of the sharp peak. The average estimated value of the crystallite size of $\mathrm{ZnO}$ NPs without and with $A$. indica dye were $25 \mathrm{~nm}$ and $20 \mathrm{~nm}$ individually. The natural dye of $A$. indica leaf extracts contains different reducing factors, such as phytochemicals and enzymes, which carry out the significant reaction involved in the green synthesis of ZnO NPs. The dye extracts of leaves stabilize the NPs and stop them from aggregating [26].

\subsection{Morphological Analysis}

The peripheral morphology of ZnO NPs without and with $A$. indica dye extracts stood primarily using the scanning electron microscopy (SEM) (Ipvnano, Pune, India) analysis, and the subsequent images are shown in Figure 2. Using the ImageJ method [27], the diameter of the grain-sized cluster $\mathrm{ZnO}$ was estimated. The morphological features of both samples were considerably different based on the observed SEM estimation. The average diameter of the ZnO grain-sized NPs cluster was $(701.79 \pm 176.21) \mathrm{nm}$ without dye extracts and $(489.99 \pm 112.96) \mathrm{nm}$ with $A$. indica dye extracts. This finding suggests that the addition of $A$. indica dye extracts affects the morphology of thin films. Furthermore, the $\mathrm{ZnO}$ NPs were less aggregated and agglomerated for the A. indica dye extracts. This may be due to the strong kinship among them, which results in less accumulation or collection [24]. As a consequence, $A$. indica dye extracts greatly increase NP constancy and collection, and A. indica dye extracts lowered the diameter of $\mathrm{ZnO}$ NPs [25].
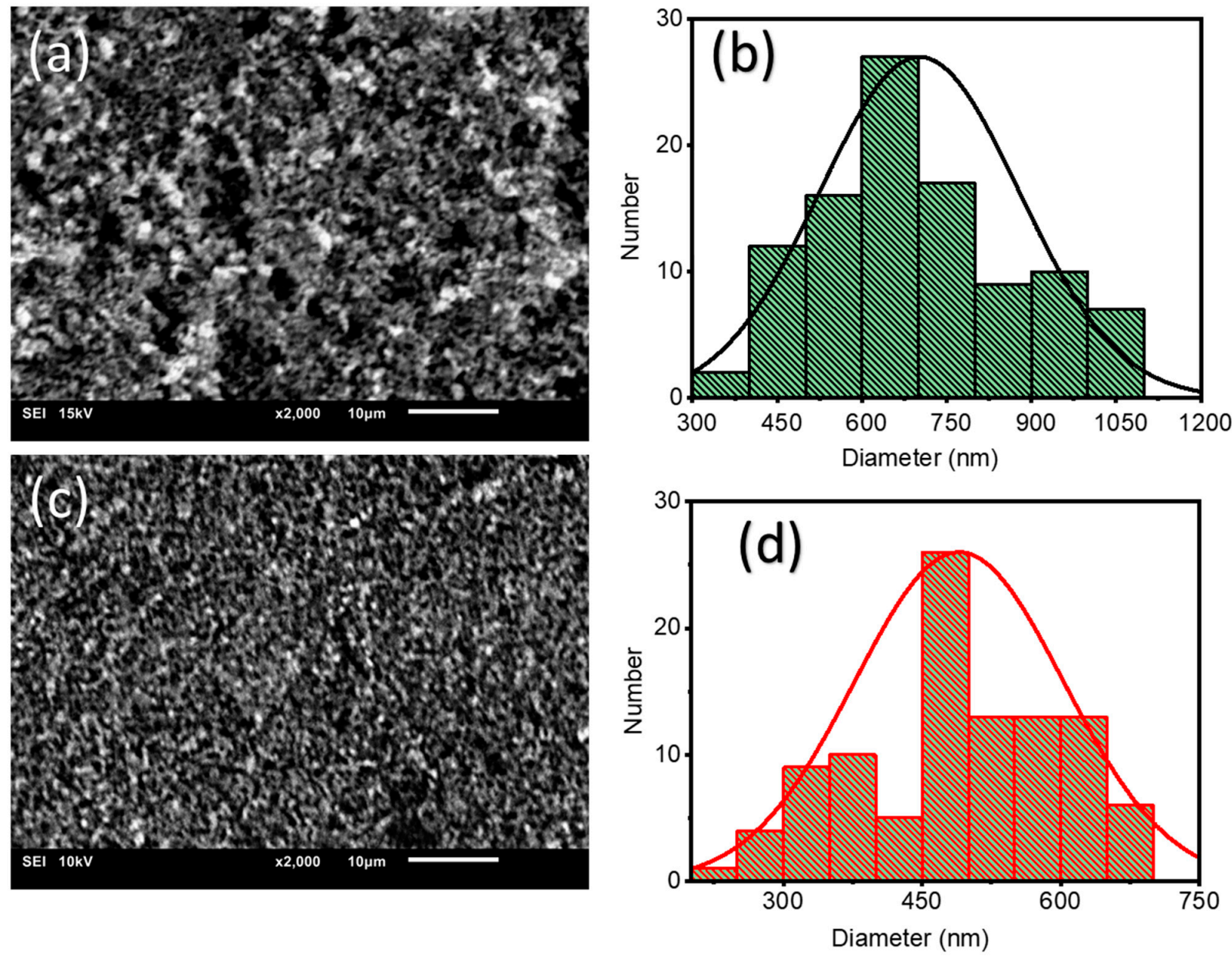

Figure 2. SEM images and cluster size distribution of the ZnO NP cluster at (a,b) $10 \mu \mathrm{m}$ scale (without dye extracts) and (c,d) $10 \mu \mathrm{m}$ scale (with $A$. indica dye extracts). 


\subsection{Energy-Dispersive X-ray Analysis}

Figure 3 presents the energy-dispersive X-ray (EDX) (Ipvnano, Pune, India) spectra of the ZnO NPs without and with $A$. indica dye extracts. The EDX spectra showed the presence of $\mathrm{Zn}$ and $\mathrm{O}$ in the synthesized NPs and the purity of the prepared $\mathrm{ZnO}$ NPs. The sharp peaks at 1.0, 8.5, and $9.5 \mathrm{keV}$ in the figure indicate the appearance of zinc, and the peak at $0.5 \mathrm{keV}$ reflected the presence of oxygen. The atomic composition of the bare $\mathrm{ZnO}$ NPs was 51.37 and $48.63 \%$ for zinc and oxygen, respectively. The atomic spreading of the $A$. indica dye extracts was $50.03 \%$ for zinc and $49.97 \%$ for oxygen. The introduction of A. indica dye helped to increase the oxygen ratio slightly to the prepared ZnO NPs, which may be due to the presence of water-soluble proteins from plant extracts. Thus, from the above configuration results, we can easily confirm that the synthesized ZnO NPs of both samples gained a high degree of purity.

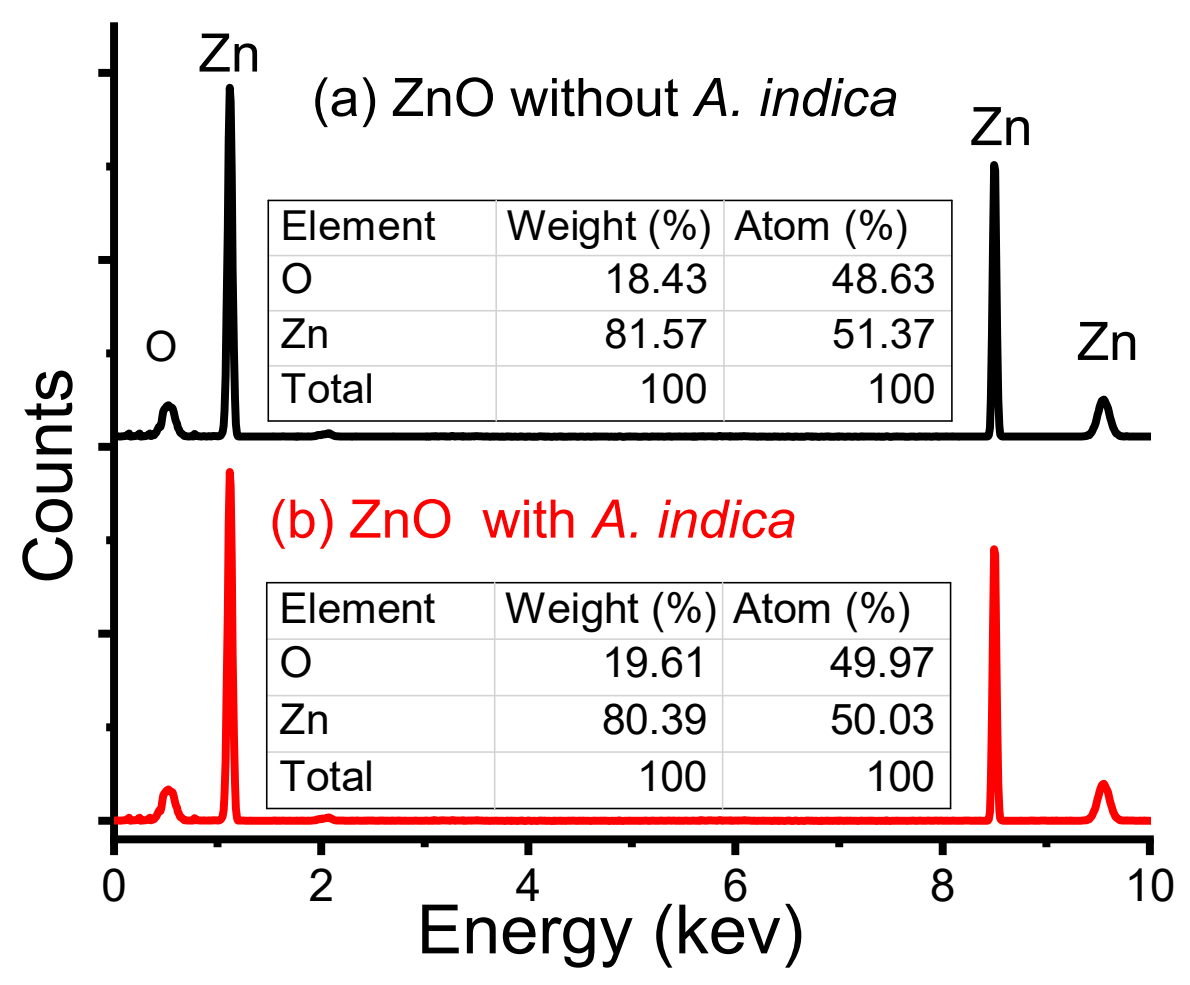

Figure 3. EDX spectra of ZnO NPs (a) without $A$. indica dye extracts and (b) with $A$. indica dye extracts.

\subsection{Fourier Transform Infrared Spectroscopy Analysis}

The Fourier transform infrared (FTIR) (Chem Tech Pro, 4100, Gujarat, India) spectrum presented in Figure 4 was applied to examine the cleanliness and arrangement of $\mathrm{ZnO}$ NPs without and with $A$. indica dye extracts. For both samples, the peaks at 450 and $527 \mathrm{~cm}^{-1}$ are the typical absorption of $\mathrm{ZnO}$ [28]. The spectra shown at $630-660 \mathrm{~cm}^{-1}$ are attributed to the occurrence of N-H stretching bonds and the peaks between 837 and $850 \mathrm{~cm}^{-1}$ are due to C-H stretching of aromatics [29]. The bands at 977 and $1094 \mathrm{~cm}^{-1}$ correspond to the C-N stretching of alcohol and phenolic groups, aliphatic amines, and aliphatic and aromatic amides [29]. Similarly, the spectrum bands illustrated between 1105 and $1579 \mathrm{~cm}^{-1}$ can be attributed to $\mathrm{O}-\mathrm{H}$ and $\mathrm{C}-\mathrm{OH}$ stretching vibration of polyols [30]. The extensive band at $1618 \mathrm{~cm}^{-1}$ might likely remain due to the $\mathrm{C}=\mathrm{C}$ elongation of aromatic rings [30]. The band created at $2912 \mathrm{~cm}^{-1}$ likely correlated to the C-H stretching of polyols [31]. In addition, the bands at 3400,3430 , and $3615 \mathrm{~cm}^{-1}$ correlated with the $\mathrm{O}-\mathrm{H}$ widening of the phenolic compounds in the dye extracts [31]. 


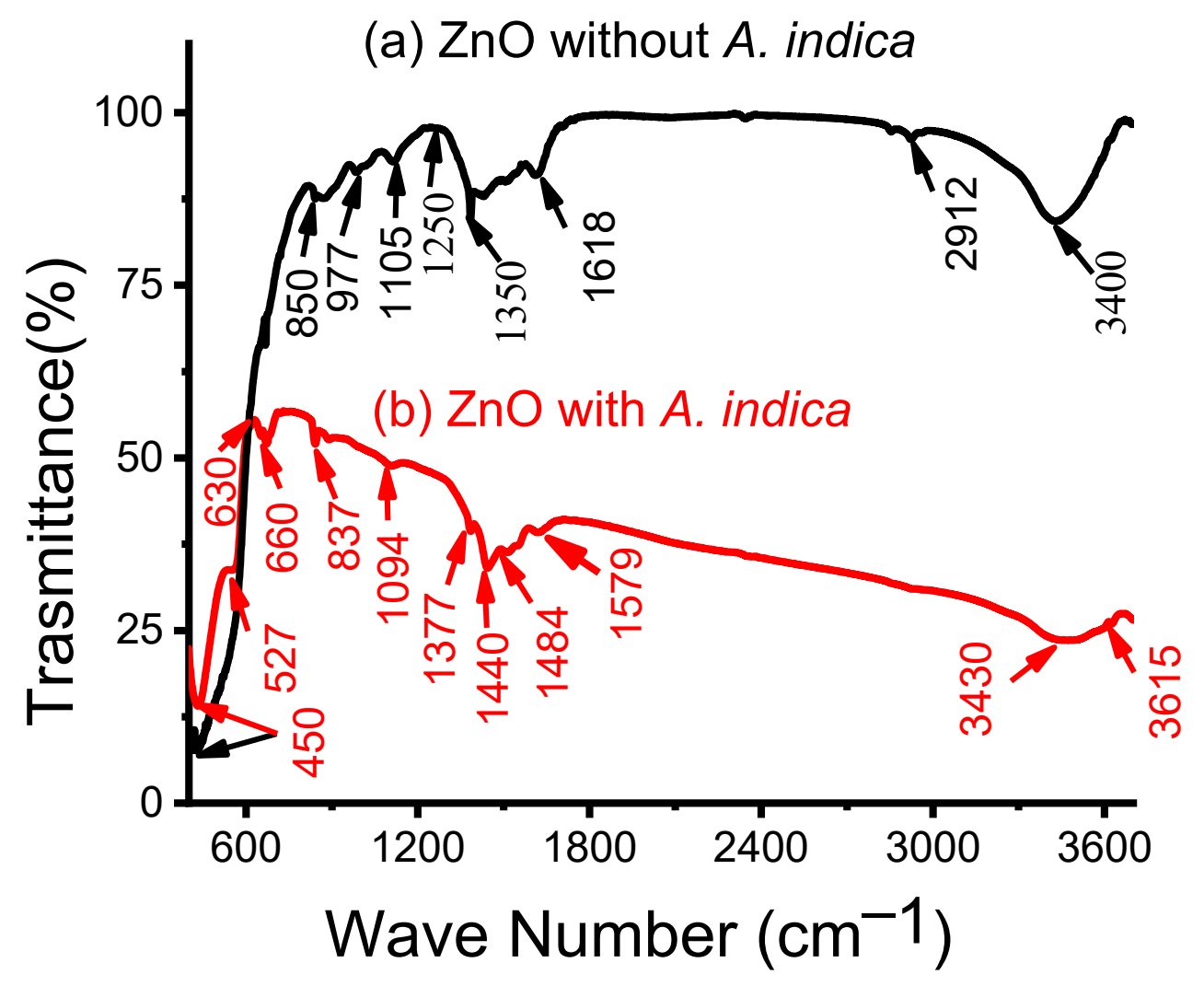

Figure 4. FTIR analysis of ZnO NPs (a) without dye extracts, (b) with A. indica dye extracts.

The peaks viewed in FTIR spectra of ZnO NPs after addition of $A$. indica such as 3615, $3430,1579,1484,1440,1094,837$, and $660 \mathrm{~cm}^{-1}$ show the presence of polyols, terpenoids, and proteins partaking functional groups of amines, alcohols, ketones, and carboxylic acid in bio-reduction responses [26]. Raphael et al. reported that proteins obtained from $A$. indica acted as a green reductant for the synthesis of NPs [32]. Terpenoids, polyols, free amino groups, carboxylic groups, alcohols, and ketones derived from $A$. indica leaf extracts play a significant role in bio-reduction reactions that are responsible for the reduction of zinc ions into $\mathrm{ZnO}$ NPs [23]. In addition, the several amide groups of proteins act as capping material that avoids agglomeration and makes ZnO NPs more stable [33]. Thus, the soluble substances present in the dye of $A$. indica could have acted as a capping and stabilizing agent, which averts the accumulation of NPs in the solution and plays an important part in the extracellular forge and shaping of $\mathrm{ZnO}$ NPs [34]. Thus, from the above results we may conclude that the soluble substances present in the dye of $A$. indica could have acted as a capping and stabilizing agent, which averts the accumulation of NPs in the solution and plays a significant role in the extracellular forge and shaping of ZnO NPs.

\subsection{Sensitivity Analysis}

Here, thin films of $\mathrm{ZnO}$ without and with $A$. indica dye extracts were coated on FTO substrates. The resistance of the FTO before and after coating the $\mathrm{ZnO}$ thin films was measured. The resistance of the FTO increased after the coating of thin films for both samples, confirming the $\mathrm{ZnO}$ thin film deposition. In this study, the response of $\mathrm{ZnO}$ thin films was measured with respect to the change in resistance before and after the injection of ethanol vapor. The response of an N-type semiconductor of metal oxide thin film gas sensor for reducing gases can be calculated by using Equation (1) [32].

$$
R=\frac{R_{a}-R_{g}}{R_{a}} \times 100 \%
$$


where $R$ is the response of a thin film in terms of change in resistance, $R_{a}$ is the air resistance, and $R_{g}$ is the gas resistance. One hundred parts per million of ethanol were injected into the sensing chamber, and the resistance of the $\mathrm{ZnO}$ thin film at different temperatures in air and ethanol vapor was measured. The sensing performance of the $\mathrm{ZnO}$ films was then studied. The optimization of the operational temperature is mandatory before measuring the response of the $\mathrm{ZnO}$ thin film. The response measurements of $\mathrm{ZnO}$ films without and with $A$. indica dye extract in the temperature range of $50-325^{\circ} \mathrm{C}$ of ethanol vapor are shown in Figure 5. A maximum response of $51.13 \%$ and $71.95 \%$ were obtained for the $\mathrm{ZnO}$ thin film without and with dye extracts at an operating temperature of $250{ }^{\circ} \mathrm{C}$ and $225^{\circ} \mathrm{C}$, respectively. The introduction of $A$. indica dye extracts slightly decreased the operating temperature from $250^{\circ} \mathrm{C}$ to $225^{\circ} \mathrm{C}$. The decline in operating temperature on the addition of $A$. indica dye extracts may be due to a decrease in activation energy of the reaction in the $\mathrm{ZnO}$ thin film [4]. Oxygen vacancies play an important role in varying the conductivity and hence the response of $\mathrm{ZnO}$ thin films [35,36]. On increasing the temperature, the response increases; when the thermal energy reaches the boundary to bridge the activation energy barrier of the reaction, the charge volume dramatically increases and causes a high response behavior. After crossing the optimum temperature, desorption of oxygen molecules occurs from the $\mathrm{ZnO}$ thin film, which decreases the response [13].

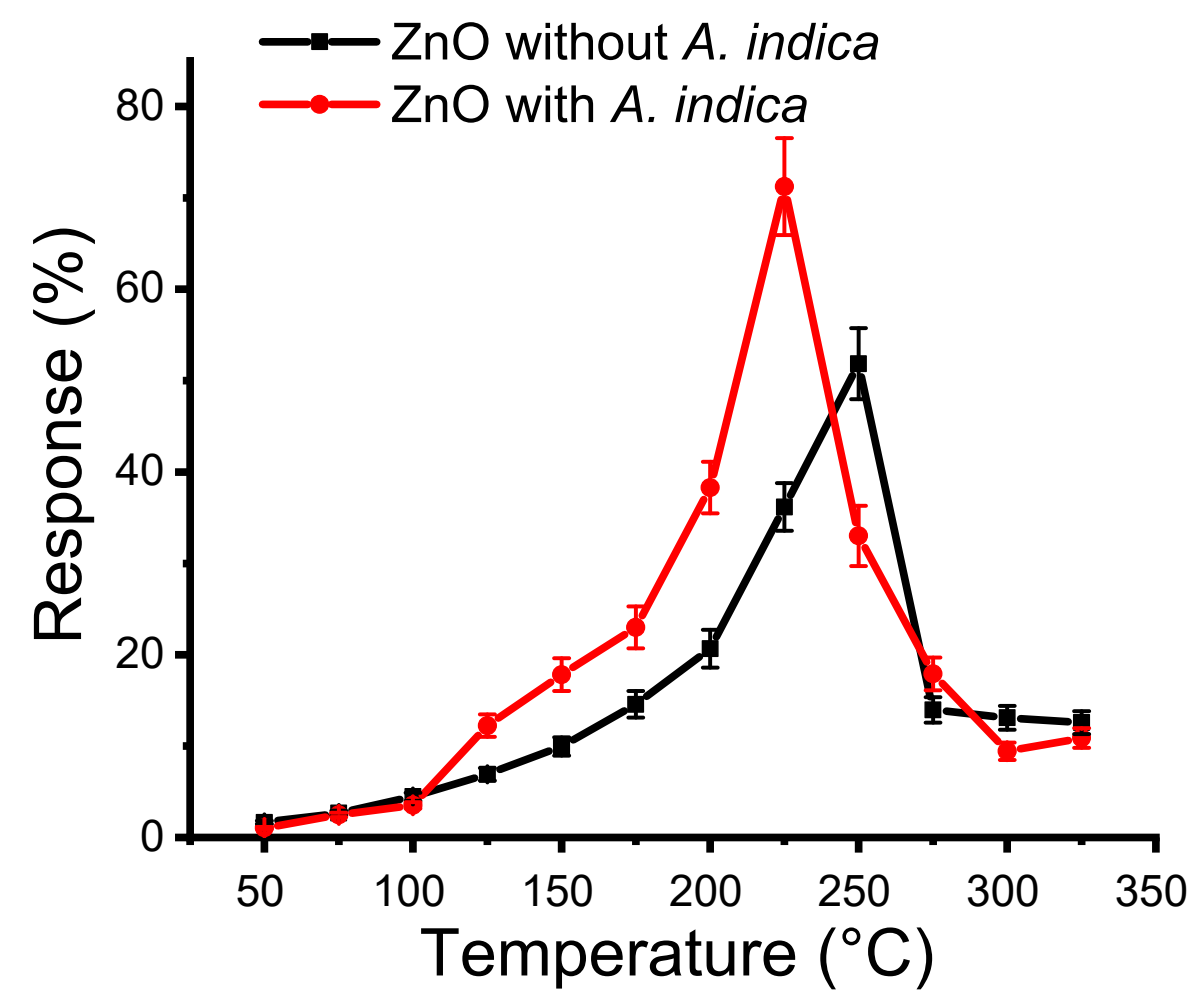

Figure 5. Response measurement as a function of temperature for $\mathrm{ZnO}$ thin films without and with A. indica dye extracts for ethanol vapor.

The response of an ethanol gas sensor was increased dramatically when $A$. indica dye extract was introduced in $\mathrm{ZnO}$ NPs. The natural capping agents present in $A$. indica dye extracts decreased both the grain and crystallite size of ZnO NPs [37]. The decrease in the grain size of $\mathrm{ZnO}$ NPs leads to significant increase in the specific surface area, which leads to high activity by adsorbing more oxygen molecules, and helps to enhance the response [38]. Moreover, the geometric dimensions of nanocrystalline and molecular sizes are comparable, which predetermines the difference between the kinetics of chemical transformations in nanocrystalline systems and similar processes in coarsely crystalline materials [39]. These specific features make $\mathrm{ZnO}$ thin films very promising for development 
of high-sensitivity fast-response gas sensors, in which just surface processes play the key role in the formation of a sensor signal.

The response characteristics of the ZnO NPs films on the exposure of 25, 50, 75, and $100 \mathrm{ppm}$ of ethanol were studied. For the purpose of computing response, each sample was analyzed five times, and the average result for each sample are displayed in Figures 6 and 7. For varying concentrations of ethanol, Figure 6a shows the behavior of the $\mathrm{ZnO}$ thin film without and with $A$. indica dye extracts. Clearly, the response increased for higher concentration of ethanol for both cases. At 25, 50, 75, and $100 \mathrm{ppm}$ ethanol, pure $\mathrm{ZnO}$ thin films responded with $39.58,40.71,40.77$, and $51.13 \%$, respectively; however, the response of $A$. indica doped $\mathrm{ZnO}$ thin films was $50.52,56.19,61.95$, and $71.95 \%$, respectively. Figure $6 \mathrm{~b}$ depicted the curve of sensor resistance against time for $\mathrm{ZnO}$ thin films without and with $A$. indica dye extracts at $25,50,75$, and $100 \mathrm{ppm}$ ethanol concentrations at 250 and $225^{\circ} \mathrm{C}$. The sensor element is exposed to an air-ethanol mixture before being discharged back into the atmosphere. When exposed to air, the sensor's resistance is strong, but it drops dramatically when exposed to ethanol. The $\mathrm{ZnO}$ semi-conductor gas sensor exhibited similar behavior $[1,40,41]$. The response rate and recovery rate are also important parameters in a gas sensor [42]. The measurement process of response and recovery times is shown in Figure 6c. For all ethanol concentrations, the response of $A$. indica dye extracts $\mathrm{ZnO}$ thin films is always greater than that of pure $\mathrm{ZnO}$ thin films, as shown in Figure 6d.

(a)

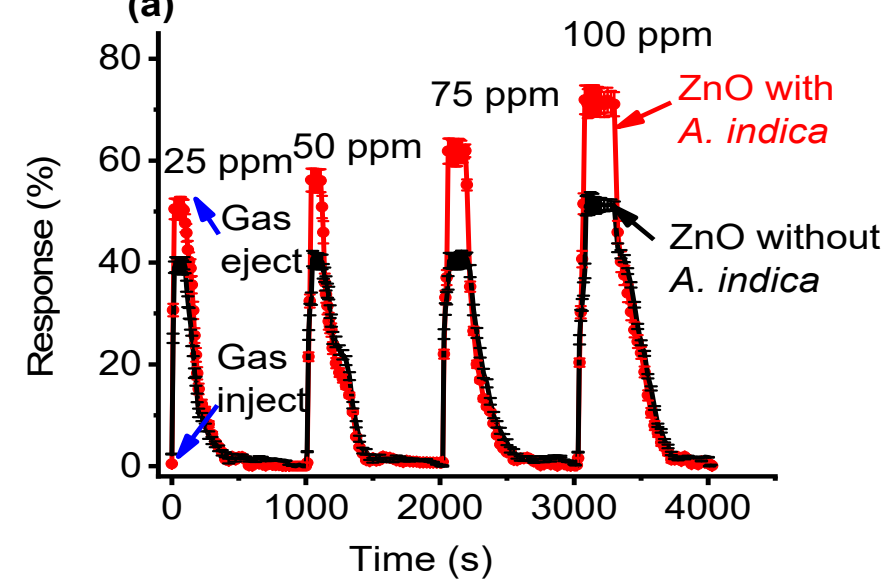

(c) For $25 \mathrm{ppm}$ of ethanol

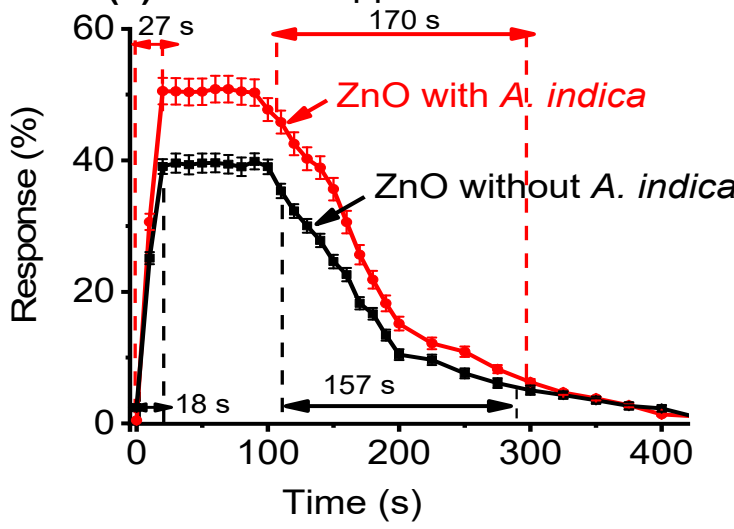

(b)

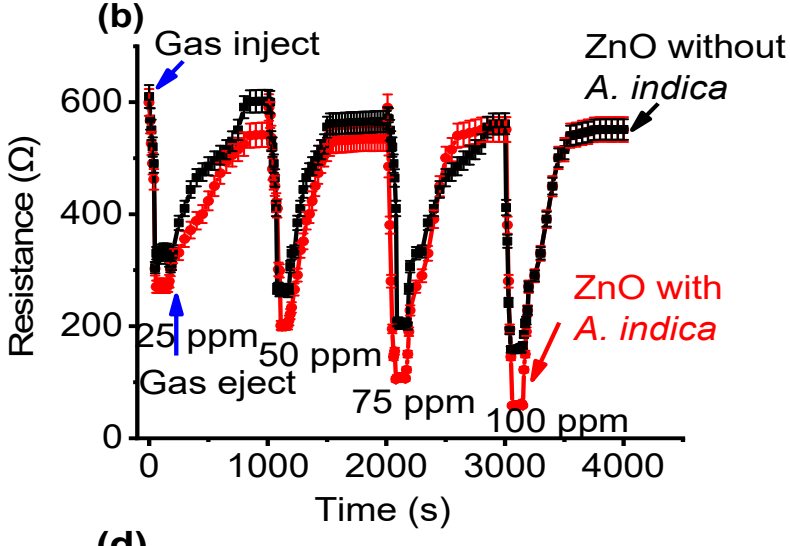

(d)

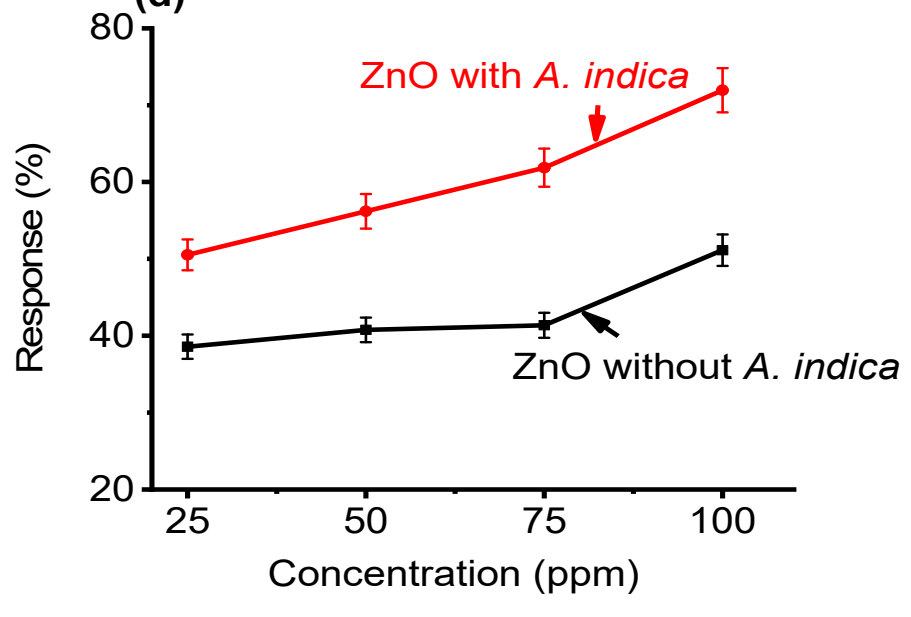

Figure 6. (a) Sensitivity measurement of $\mathrm{ZnO}$ thin films as a function of time. (b) Response curve with time scale and sensor resistance for 25, 50,75, and $100 \mathrm{ppm}$ ethanol at operating temperature. (c) Calculation of the response and recovery time of $\mathrm{ZnO}$ thin film for $25 \mathrm{ppm}$ ethanol. (d) Sensitivity measurement of $\mathrm{ZnO}$ thin films as a function of concentration. 
(a)

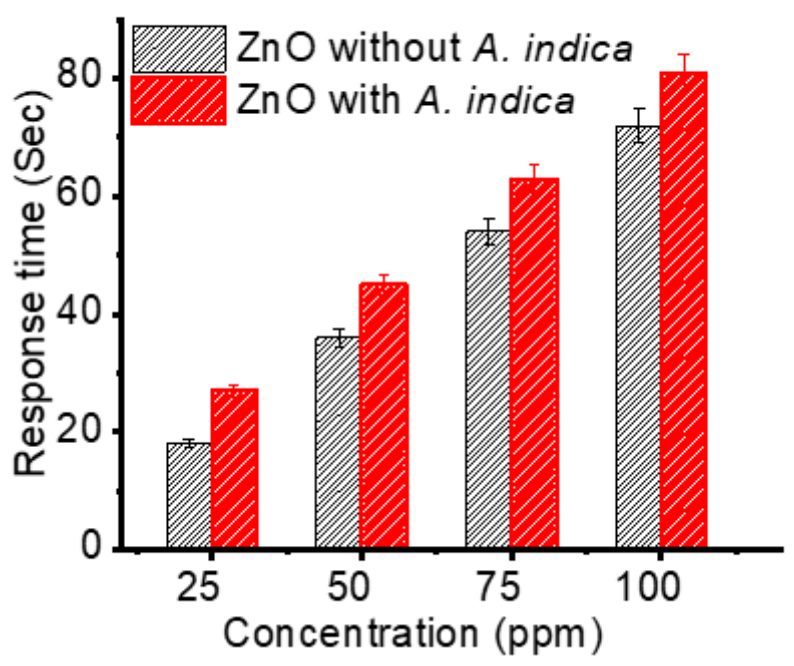

(b)

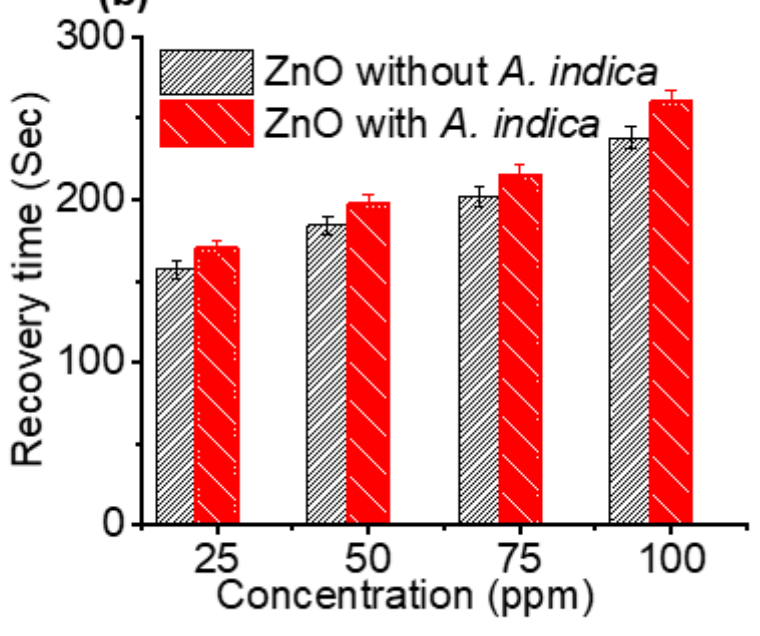

Figure 7. (a) Response time of $\mathrm{ZnO}$ thin films as a function of concentration and (b) recovery time of $\mathrm{ZnO}$ thin films as a function of concentration.

Subsequently, response and recovery times as a function of concentration were investigated, as shown in Figure 7. The average response time for bare $\mathrm{ZnO}$ thin films with 25, 50,75 , and $100 \mathrm{ppm}$ of ethanol was $18,36,54$, and $72 \mathrm{~s}$, respectively, whereas the average response time for $A$. indica extracts was 27, 45, 63, and $81 \mathrm{~s}$ (Figure 7a). Similarly, the average recovery time for bar $\mathrm{ZnO}$ thin films with 25, 50, 75, and $100 \mathrm{ppm}$ of ethanol was $157,184,202$, and 238 s, respectively, whereas the mean recovery time for $A$. indica extracts was 170, 197, 215, and $260 \mathrm{~s}$ (Figure 7b). The response and recovery times of the $\mathrm{ZnO}$ thin film increased with the addition of $A$. indica dye extracts at ethanol concentrations ranging from $25 \mathrm{ppm}$ to $100 \mathrm{ppm}$. This is due to the increased carrier concentration in the $\mathrm{ZnO}$ thin film after the $A$. indica dye extract doping. The oxygen adsorption process is the main factor determining the rate of response and recovery cycles [43]. The increasing response and recovery time for $\mathrm{ZnO}$ with $\mathrm{A}$. indica dye extracts are attributed to the modification of the $\mathrm{ZnO}$ surface morphology and increased porosity between the grain- sized $\mathrm{ZnO}$ nanostructures, which provide more surface-active sites to promote interaction with ethanol vapor [44].

\subsection{Sensing Mechanism}

The response features of the ethanol-based gas sensor using $\mathrm{ZnO}$ thin films are directly linked to the modification of ZnO NPs. Here, the resistance of the thin film decreased with the supply of ethanol vapor in the sensing device, as shown in Figure $6 \mathrm{~b}$. The oxygen present in the atmosphere gets absorbed on the $\mathrm{ZnO}$ film as $\mathrm{O}^{2-}$ or $\mathrm{O}^{-}$, taking electrons from the conduction band of the $\mathrm{ZnO}$ and resulting in a depletion zone on the $\mathrm{ZnO}$ thin film [4]. This process increased the resistance of the $\mathrm{ZnO}$ thin film significantly. On the exposure of ethanol vapor, the ethanol vapor molecules interact with the absorbed oxygens and reinject the carrier, thereby decreasing the resistance of the $\mathrm{ZnO}$ thin film [45]. This effect is relatively higher in $\mathrm{ZnO}$ thin films using $A$. indica dye extracts than in thin films without dye. Therefore, the $\mathrm{ZnO}$ thin film with $A$. indica extracts shows a large gap in resistance between with ethanol vapor and without ethanol vapor in the sensing device, leading to an increase in the response of the device. The probability of the interaction of ethanol vapor with the $\mathrm{ZnO}$ thin film can be explained in Figure 8, as noted in previous literature [46]. 


\section{Surface \\ Oxygen ions}

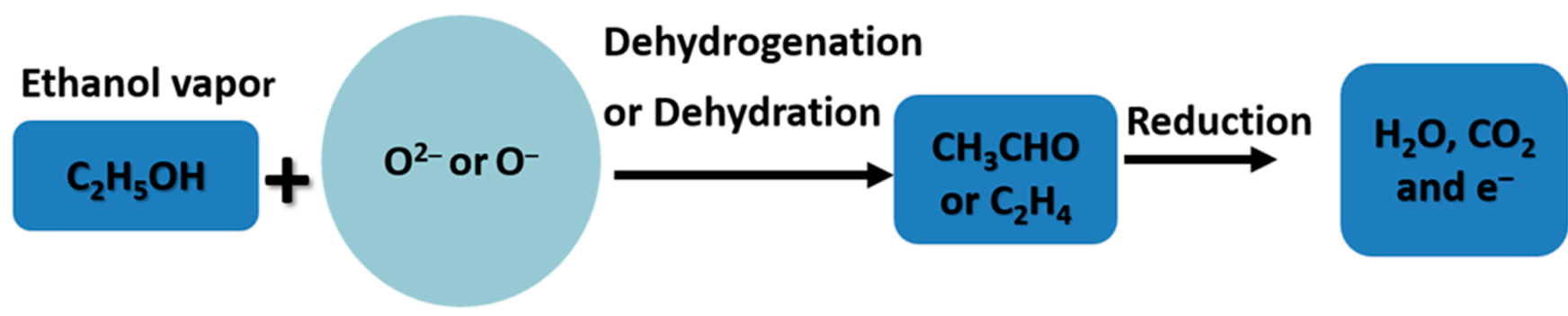

Figure 8. Gas response mechanism of the $\mathrm{ZnO}$ thin film based on ethanol vapor.

The approved reactions are initiated by the acid-alkaline behavior of the $\mathrm{ZnO}$ thin film. The dehydrogenation procedure mainly occurs on the $\mathrm{ZnO}$ thin film with alkaline possessions; however, dehydration is preferred in the acidic region of the $\mathrm{ZnO}$ thin film [47]. At determined temperatures $\left(<200^{\circ} \mathrm{C}\right)$, more gaseous elements are adsorbed, depletion area formed on the thin film of $\mathrm{ZnO}$ extends intensely, providing a large possibility of interacting ethanol vapor molecules with adsorbed oxygens, thereby generating an improved response [5]. The $\mathrm{ZnO}$ thin film with $A$. Indica dye adsorbed more oxygen than that of the pure $\mathrm{ZnO}$ thin film because of large specific surface area and desorption of function groups attached with thin film at higher temperatures [48]. This effect caused high possibility of interaction of ethanol vapor molecules with oxygen, resulting in a significant decrease in the resistance of the film, which increased the response. However, at low temperatures, the surface of the $\mathrm{ZnO}$ thin film was not perfectly desorbed, which caused a small change in resistance. This slight change in resistance significantly decreased the sensing properties of the $\mathrm{ZnO}$ thin film.

\section{Materials and Methods}

\subsection{Synthesis of ZnO NPs without Plant Extracts}

$\mathrm{ZnO}$ NPs were prepared using the precipitation method. Initially, a $2 \mathrm{M}$ zinc nitrate hexahydrate $\left[\mathrm{Zn}\left(\mathrm{NO}_{3}\right)_{2} \cdot 6 \mathrm{H}_{2} \mathrm{O}\right]$ mixture was prepared in ethanol with continuous stirring using a magnetic stirrer for an hour (h) [49]. Concurrently, a $1 \mathrm{M}$ ethanol solution of sodium hydroxide $\left[\mathrm{C}_{2} \mathrm{H}_{7} \mathrm{NaO}_{2}\right]$ was prepared with continuous stirring using a magnetic stirrer for $2 \mathrm{~h}$ in a different beaker. Likewise, an ethanol solution of sodium hydroxide zinc nitrate solution was added dropwise to the zinc nitrate solution with robust stirring to produce a white precipitate. After total inclusion, the blend was allowed to settle for $1 \mathrm{~d}$. Finally, the resulting precipitate was centrifuged four times at $1000 \mathrm{rpm}$ (centrifuge model 800-B, China), with $10 \mathrm{~min}(\mathrm{~m})$ each time, for the removal of contaminants. The precipitate was then cleaned three times using distilled water, followed by ethanol. Finally, the filtered white precipitate was dried at $120^{\circ} \mathrm{C}$ and then annealed at $500^{\circ} \mathrm{C}$ using a muffle furnace (BOECO Muffle Furnace, MF 8/1100, 230 V, 50/60 Hz, Lilienthal, Germany) for 12 h [49].

\subsection{Synthesis of $\mathrm{ZnO}$ with A. indica Dye Extracts}

Fresh leaves of $A$. indica were washed several times using distilled water and dehydrated at room temperature. The leaf extracts were then ground, $10 \mathrm{~g}$ of ground leaves were mixed in $40 \mathrm{~mL}$ of distilled water, and the mixture of leaves and distilled water was filtered to remove solid extracts. Finally, the fine solution of $A$. indica leaves and distilled water was preserved in a refrigerator at $4{ }^{\circ} \mathrm{C}$. A $2 \mathrm{M}$ zinc nitrate hexahydrate solution was prepared in distilled water under vigorous stirring. After vigorous stirring, $10 \mathrm{~mL}$ of aqueous leaf extracts of $A$. indica were introduced into the above solution, and a $1 \mathrm{M}$ ethanol solution of sodium hydroxide was mixed in the above mixture dropwise and stirred thoroughly to obtain a white precipitate. The mixture containing the white precipitate was then stirred using a magnetic stirrer for $2 \mathrm{~h}$. After stirring, the mixture was washed three times with 
distilled water and ethanol and then filtered. Finally, the filtered white precipitate was dried at $120^{\circ} \mathrm{C}$ and then annealed at $500{ }^{\circ} \mathrm{C}$ using a muffle furnace. A schematic of the synthesis of $\mathrm{ZnO}$ using the green scheme is illustrated in Figure 9.

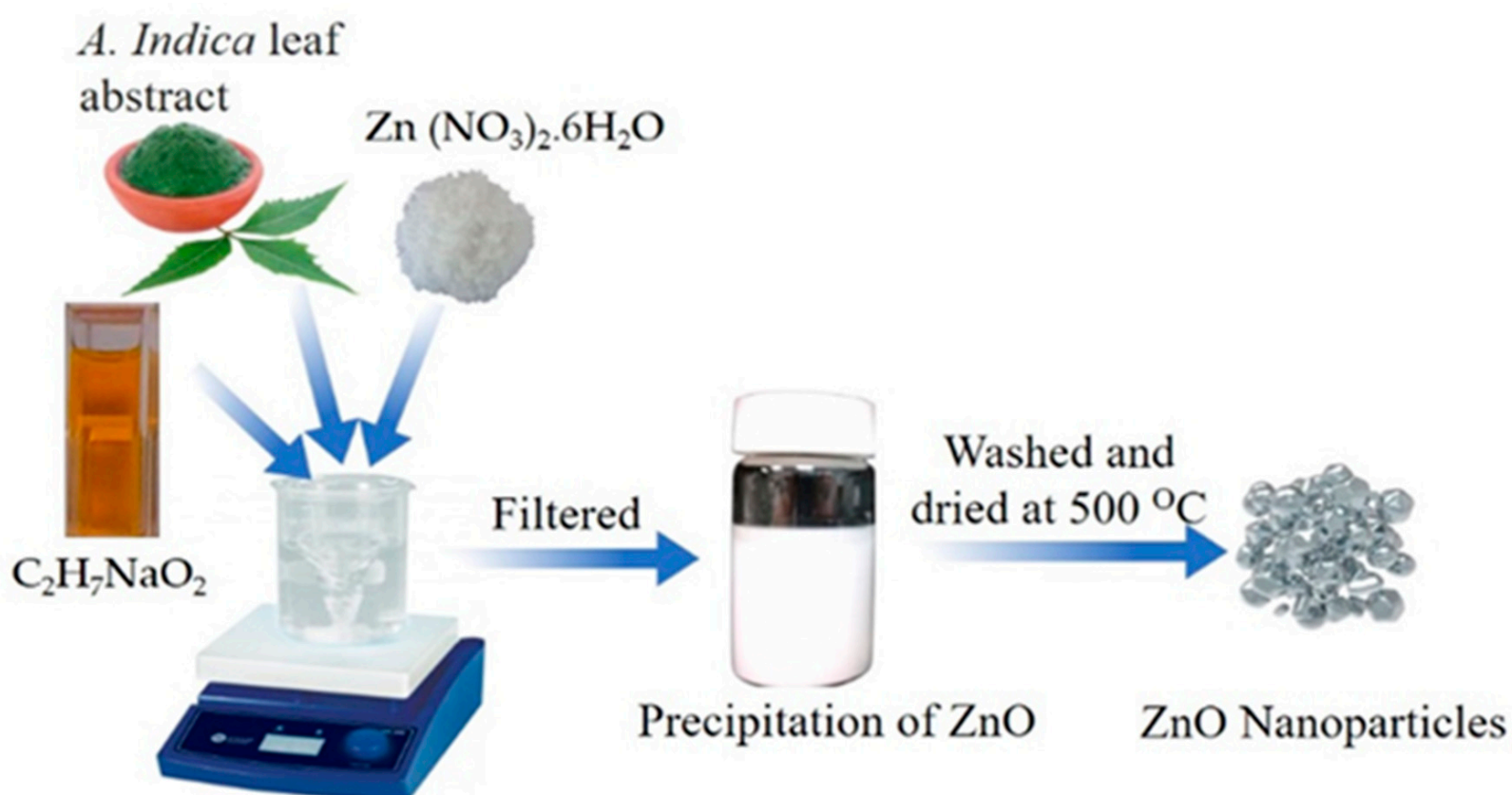

Stirred for $1 \mathrm{~h}$

Figure 9. Schematics of the synthesis of $\mathrm{ZnO}$ using the green scheme.

\subsection{Synthesis of $\mathrm{ZnO}$ Thin Films}

$\mathrm{ZnO}$ thin film was deposited on the FTO coated glass substrate using the spray pyrolysis technique. This method is especially convenient for the settling of ZnO NPs and has been a measurement method for applying a clear electrical conductor of metal oxides to a glass surface [5]. In this process, as shown in Figure 10, the spraying rate remains the same, and the back and forth motions of the machine determine the number of coats, which is digitally controlled. The main benefits of using the spray pyrolysis technique are the spherical surface shape, narrow distribution of atoms or molecules, compilation uniformity, and height controllability of the arrangement of the obtained products and their appropriateness for succeeding refining [50].

A precursor solution was prepared by taking $4.06 \mathrm{~g}$ of $\mathrm{ZnO}$ in a beaker with $50 \mathrm{~mL}$ of ethanol. The solution was mixed using a magnetic stirrer for $1 \mathrm{~h}$ at a temperature of $60{ }^{\circ} \mathrm{C}$. The resulting solution was filtered using a filter paper and used to prepare thin films using the spray pyrolysis method. The distance from the nozzle to the glass substrate was $2.0 \mathrm{~cm}$, the diameter of the nozzle was $0.5 \mathrm{~cm}$, and the flow rate was maintained at $8 \mathrm{~mL} / \mathrm{min}$. The operating pressure range was maintained between 8 and $16 \mathrm{psi}$. The spray pyrolysis process included the deposition of $\mathrm{ZnO}$ thin films in which the dispersed solution of $\mathrm{ZnO}$ NPs prepared with ethanol was sprayed uniformly on the glass substrate over the heated surface at $300^{\circ} \mathrm{C}$. This method yields a very uniform thin film of $\mathrm{ZnO}$ owing to the constant spray rate of the nozzle of the spray gun. 


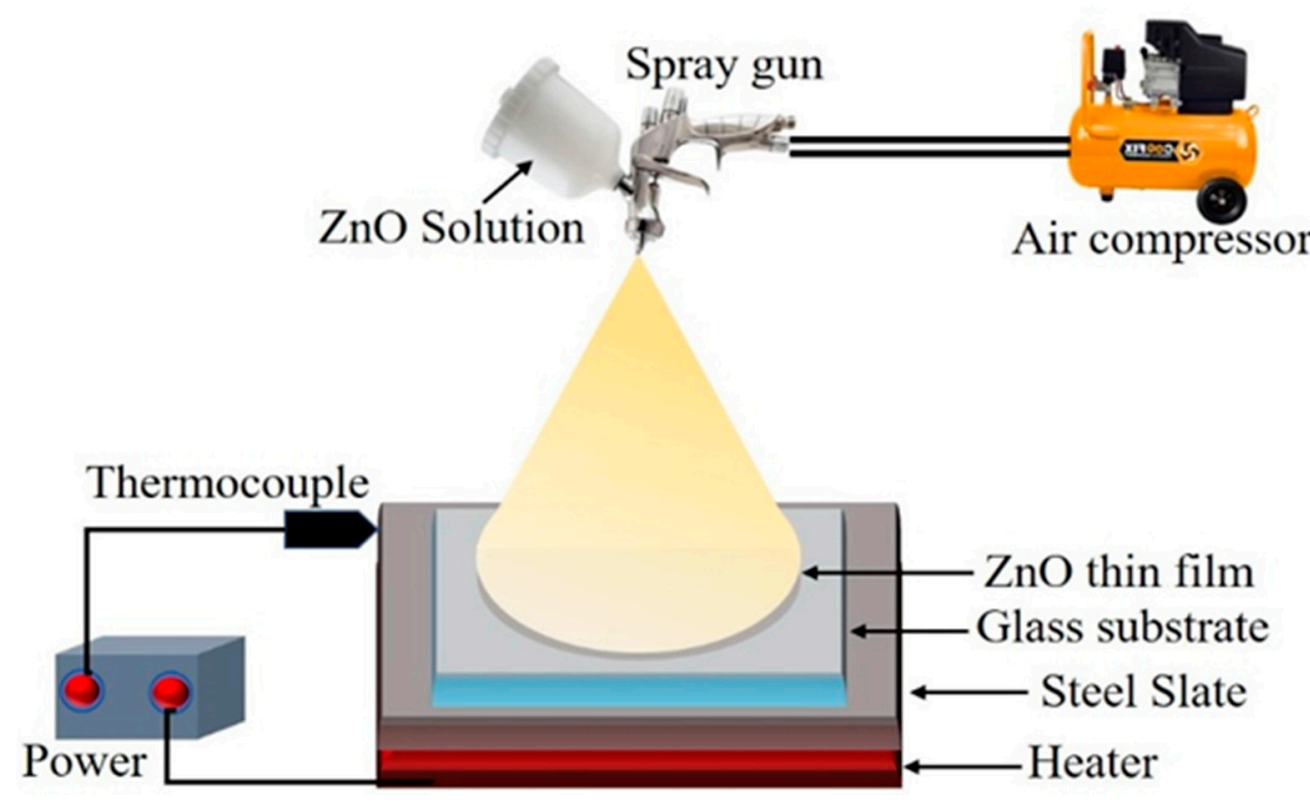

Figure 10. Schematic diagram of the spray pyrolysis method.

\subsection{Sensor Application}

The response was measured using a custom-made ethanol gas sensor as shown in Figure 11. A nickel-chromium heater was used to heat the sensing element placed just below it, and it could be heated up to $350{ }^{\circ} \mathrm{C}$. A thermocouple was used to monitor the temperature of the sensing element. The temperature controller was set up to maintain the temperature of the glass substrate from $90{ }^{\circ} \mathrm{C}$ to $350{ }^{\circ} \mathrm{C}$. The source and drain were fabricated in the $\mathrm{ZnO}$ thin film with the help of insulating copper wire using the silver paste and then connected to a fluke multimeter (FLUKE-115, Everett, WA, USA) for resistance measurement. To measure the resistance after injecting the gas, the glass chamber was made airtight. The circuit configuration of the gas sensor was checked by using current-voltage characterization followed by ohmic behavior. The total volume of the sensor chamber is one liter (L). The distance between the base of the sensor chamber and the $\mathrm{ZnO}$ thin film is $5 \mathrm{~cm}$. A syringe injects a fixed amount of liquid ethanol $(25,50,75$, or $100 \mathrm{ppm})$ into the airtight test chamber to achieve the desired concentration. The ethanol concentration calculation method is described in Equations (2)-(4) [51]:

$$
V_{\text {ethanol gas }}=C \times V_{s}
$$

where $V_{\text {ethanol gas }}=$ volume of gaseous state ethanol, $C(\mathrm{ppm})=$ concentration of the ethanol gas, and $V_{S}=$ volume of tested chamber with, $P V=n R T$ [51].

$$
n_{\text {ethanol }}=\frac{P V_{\text {ethanol gas }}}{R T}=\frac{P C V_{s}}{R T}
$$

where $V=\frac{M n}{\rho}$.

$$
V_{\text {inject }}=\frac{M n_{\text {ethanol }}}{\rho}=\frac{M P C V_{s}}{R \rho T}=\left(0.69 \times \frac{C}{T}\right) \mathrm{mL}
$$

The molecular weight of the liquid is $M(\mathrm{~g} / \mathrm{mol})$, the density is $\rho(\mathrm{g} / \mathrm{mL})$, and the average temperature of the test chamber is $T(\mathrm{~K})$. The values of $M, P, V s$, and $R$ in our work are $46 \mathrm{~g} / \mathrm{mol}, 101,325 \mathrm{~Pa}, 1 \mathrm{~L}, 8.31441 \mathrm{~J} /(\mathrm{mol} \mathrm{K})$, and $0.816 \mathrm{~g} / \mathrm{cm}^{3}$. Equation (4) can be used to compute the ethanol intended concentration. 


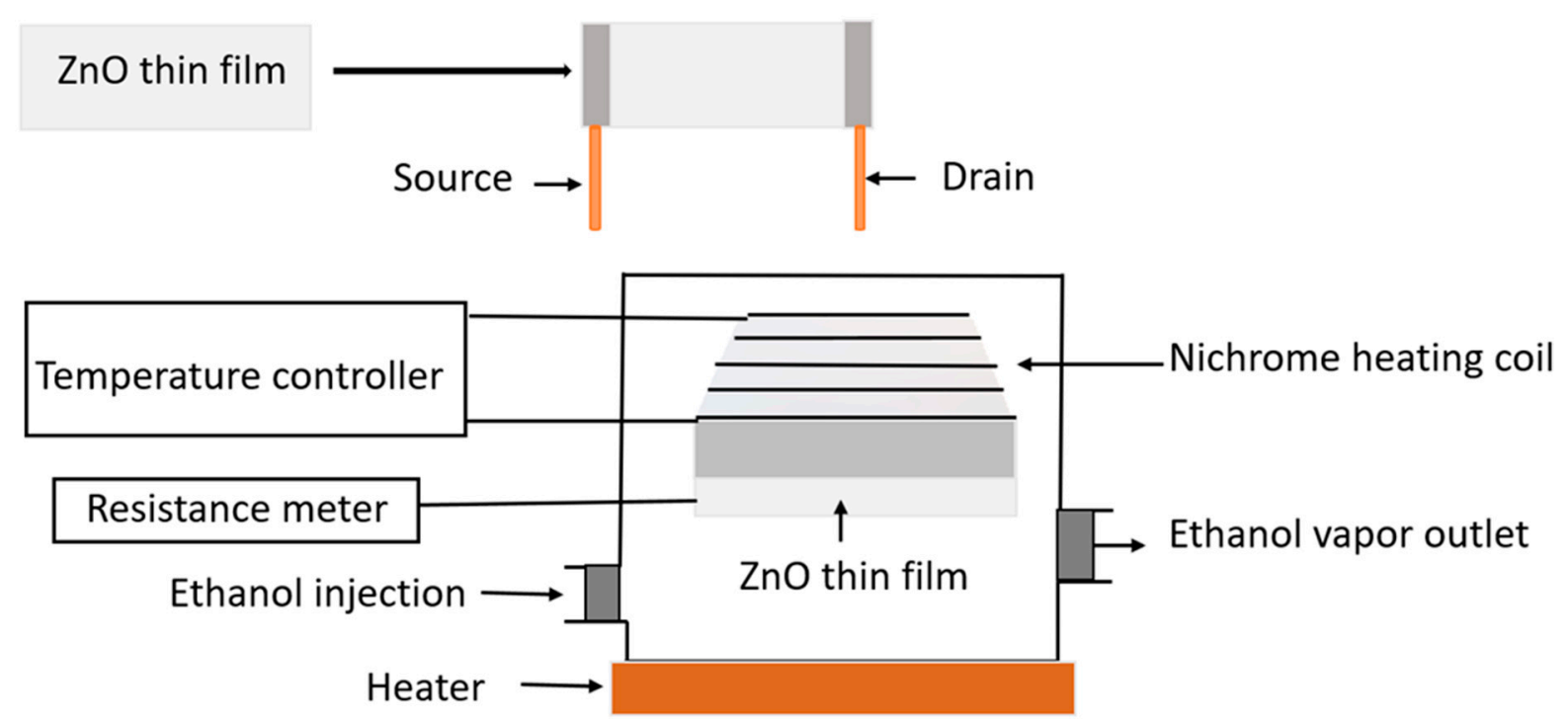

Figure 11. Schematic diagram of the gas sensor.

\section{Conclusions}

In summary, $\mathrm{ZnO}$ NPs were prepared using the precipitation method. The resulting $\mathrm{ZnO}$ NPs were coated on glass substrates using the spray pyrolysis method to prepare the thin film. The structural, morphological, and dimensional analyses of the ZnO NPs were performed using XRD, SEM, EDX, and FTIR. The XRD pattern shows that the mean crystallite size of ZnO NPs prepared without dye extracts was $25 \mathrm{~nm}$ and that of the $A$. indica dye extracts was $20 \mathrm{~nm}$. The SEM image shows the change in morphology of $\mathrm{ZnO}$ NPs from more congregated to less aggregated groups after the addition of $A$. indica dye extracts. The EDX spectra obtained to determine the percentage composition of zinc and oxygen in the synthesized samples also indicated that the prepared $\mathrm{ZnO}$ NPs were pure. The FTIR analysis showed the characteristic absorption band of the $\mathrm{ZnO}$ bond at $450 \mathrm{~cm}^{-1}$ and also revealed the presence of water-soluble proteins such as amines, alcohols, ketones, and carboxylic acid from $A$. indica dye extracts. The results of the sensitivity measurements with the ZnO NPs show high sensitivity toward $A$. indica dye extract thin films with a figure of $71.95 \%$ for $100 \mathrm{ppm}$ of ethanol. The $\mathrm{ZnO}$ thin film with $A$. indica shows significantly decreased sensor resistance for 25, 50, 75, and $100 \mathrm{ppm}$ of ethanol vapor compared to that of the $\mathrm{ZnO}$ thin film without dye extracts. The response and recovery times of the $\mathrm{ZnO}$ thin film were higher than those of the bare $\mathrm{ZnO}$ thin film between $25 \mathrm{ppm}$ and $100 \mathrm{ppm}$ of ethanol. The sensitivity measurement and calculation of response and recovery for $25 \mathrm{ppm}$ of ethanol concentration suggest that this sensing device can also be used to detect low concentrations of ethanol. To sum up, the addition of $A$. indica dye extracts to $\mathrm{ZnO}$ thin films significantly increased the sensing, response, and recovery times of the ethanol-based gas sensor.

Author Contributions: Conceptualization, T.R.A., D.K.C. and L.P.J., validation, L.P.J., R.W., N.K.K. and E.H.C. formal analysis, B.S., L.P.J., R.W., N.K.K. and E.H.C.; investigation, T.R.A., D.K.C., L.P.J. and P.L.; writing — original draft preparation, T.R.A. and P.L.; writing—review and editing, T.R.A., L.P.J., P.L., N.K.K. and E.H.C. All authors have read and agreed to the published version of the manuscript.

Funding: The authors are grateful to University Grants Commission (UGC), Nepal for providing research support under MRS/74_75/S\&T-80 for the completion of this research work. This study was also partially supported by the National Research Foundation (NRF) of Korea, funded by the Korean government 2021R1A6A1A03038785, 2021R1F1A1055694 and by the Kwangwoon University in 2021. 
Institutional Review Board Statement: Not applicable.

Informed Consent Statement: Not applicable.

Data Availability Statement: The data that support the findings of this study are available from the corresponding author upon reasonable request.

Acknowledgments: The authors would like to thank Vinaya Kumar Jha, Arjun Dhakal, Bishnu Giri, Samir Kattel, Bishnu Pokhrel, Anjila Ghimire, and Amrendra Kumar Singh for their help and support throughout the research process. We are grateful to Department of Physical science, P.D. Patel Institute of Applied Science, Charusat, Gujarat, India allotting time for XRD, SEM, and FTIR measurements. We would also like to thank International Science Program (ISP), Uppsala University, Sweden grant No. NEP-01 for their support in designing and fabricating sensor setup.

Conflicts of Interest: The authors declare no conflict of interest.

Sample Availability: Not available.

\section{References}

1. Wan, Q.; Li, Q.H.; Chen, Y.J.; Wang, T.-H.; He, X.L.; Li, J.P.; Lin, C.L. Fabrication and Ethanol Sensing Characteristics of ZnO Nanowire Gas Sensors. Appl. Phys. Lett. 2004, 84, 3654-3656. [CrossRef]

2. Yang, Z.; Huang, Y.; Chen, G.; Guo, Z.; Cheng, S.; Huang, S. Ethanol Gas Sensor Based on Al-Doped ZnO Nanomaterial with Many Gas Diffusing Channels. Sens. Actuators B Chem. 2009, 140, 549-556. [CrossRef]

3. Arshak, K.; Gaidan, I. Development of a Novel Gas Sensor Based on Oxide Thick Films. Mater. Sci. Eng. B 2005, 118, 44-49. [CrossRef]

4. Khayatian, A.; Kashi, M.A.; Azimirad, R.; Safa, S. Enhanced Gas-Sensing Properties of ZnO Nanorods Encapsulated in an Fe-Doped ZnO Shell. J. Phys. D Appl. Phys. 2014, 47, 75003. [CrossRef]

5. Chaudhary, D.K.; Ghimire, R.; Amatya, S.P.; Shrestha, S.P.; Joshi, L.P. Study on Influence of Fe Doping into ZnO Film for Ethanol Sensing. Proc. J. Phys. Conf. Ser. 2020, 1706, 12036. [CrossRef]

6. Ajmal, H.M.S.; Khan, F.; Huda, N.U.; Lee, S.; Nam, K.; Kim, H.Y.; Eom, T.-H.; Kim, S.D. High-Performance Flexible Ultraviolet Photodetectors with Ni/Cu-Codoped ZnO Nanorods Grown on PET Substrates. Nanomaterials 2019, 9, 1067. [CrossRef] [PubMed]

7. Ajmal, H.M.S.; Khan, F.; Nam, K.; Kim, H.Y.; Kim, S.D. Ultraviolet Photodetection Based on High-Performance Co-Plus-Ni Doped ZnO Nanorods Grown by Hydrothermal Method on Transparent Plastic Substrate. Nanomaterials 2020, 10, 1225. [CrossRef]

8. Yedurkar, S.; Maurya, C.; Mahanwar, P. Biosynthesis of Zinc Oxide Nanoparticles Using Ixora coccinea Leaf Extract-A Green Approach. Open J. Synth. Theory Appl. 2016, 5, 1-14. [CrossRef]

9. Kim, S.; Saeed, M.A.; Kim, S.H.; Shim, J.W. Enhanced Hole Selecting Behavior of WO3 Interlayers for Efficient Indoor Organic Photovoltaics with High Fill-Factor. Appl. Surf. Sci. 2020, 527, 146840. [CrossRef]

10. Lamichhane, P.; Adhikari, B.C.; Nguyen, L.N.; Paneru, R.; Ghimire, B.; Mumtaz, S.; Lim, J.S.; Hong, Y.J.; Choi, E.H. Sustainable Nitrogen Fixation from Synergistic Effect of Photo-Electrochemical Water Splitting and Atmospheric Pressure N2 Plasma. Plasma Sources Sci. Technol. 2020, 29, 45026. [CrossRef]

11. Tsukazaki, A.; Ohtomo, A.; Onuma, T.; Ohtani, M.; Makino, T.; Sumiya, M.; Ohtani, K.; Chichibu, S.F.; Fuke, S.; Segawa, Y.; et al. Repeated Temperature Modulation Epitaxy for P-Type Doping and Light-Emitting Diode Based on ZnO. Nat. Mater. 2005, 4, 42-46. [CrossRef]

12. Ramimoghadam, D.; Hussein, M.Z.B.; Taufiq-Yap, Y.H. Hydrothermal Synthesis of Zinc Oxide Nanoparticles Using Rice as Soft Biotemplate. Chem. Cent. J. 2013, 7, 1-10. [CrossRef]

13. Haripadmam, P.C.; John, H.; Philip, R.; Gopinath, P. Enhanced Optical Limiting in Polystyrene-ZnO Nanotop Composite Films. Opt. Lett. 2014, 39, 474-477. [CrossRef]

14. Bantz, C.; Koshkina, O.; Lang, T.; Galla, H.-J.; Kirkpatrick, C.J.; Stauber, R.H.; Maskos, M. The Surface Properties of Nanoparticles Determine the Agglomeration State and the Size of the Particles under Physiological Conditions. Beilstein J. Nanotechnol. 2014, 5, 1774-1786. [CrossRef] [PubMed]

15. Hvolbæk, B.; Janssens, T.V.W.; Clausen, B.S.; Falsig, H.; Christensen, C.H.; Nørskov, J.K. Catalytic Activity of Au Nanoparticles. Nano Today 2007, 2, 14-18. [CrossRef]

16. Dirmyer, M.R.; Martin, J.; Nolas, G.S.; Sen, A.; Badding, J.V. Thermal and Electrical Conductivity of Size-Tuned Bismuth Telluride Nanoparticles. Small 2009, 5, 933-937. [CrossRef] [PubMed]

17. Ihsan, K.; Harabbi, K.H. Restriction of Particle Size and Lattice Strain through X-ray Diffraction Peak Broadening Analysis of ZnO Nanoparticles. Adv. Phys. Theor. Appl. 2015, 49, 638-2225.

18. Sharma, R.; Chandra, B.P.; Bisen, D.P. Thermoluminescence and Optical Absorption Spectra Of Zns: Mn Nanoparticles. Chalcogenide Lett. 2009, 6, 251-255.

19. Joshi, L.P.; Khatri, B.V.; Gyawali, S.; Gajurel, S.; Chaudhary, D.K. Green Synthesis of Zinc Oxide Nanoparticles Using Ixora Coccinea Leaf Extract for Ethanol Vapour Sensing. J. Phys. Sci. 2021, 32, 15-26. [CrossRef] 
20. Basnet, P.; Chanu, T.I.; Samanta, D.; Chatterjee, S. A Review on Bio-Synthesized Zinc Oxide Nanoparticles Using Plant Extracts as Reductants and Stabilizing Agents. J. Photochem. Photobiol. B Biol. 2018, 183, 201-221. [CrossRef] [PubMed]

21. Basak, S.P.; Chakraborty, D.P. Chemical investigation of Azadirachta indica leaf (m azadirachta). J. Indian Chem. Soc. 1968, 45, 466.

22. Biswas, K.; Chattopadhyay, I.; Banerjee, R.K.; Bandyopadhyay, U. Biological Activities and Medicinal Properties of Neem (Azadirachta indica). Curr. Sci. 2002, 82, 1336-1345.

23. Bhuyan, T.; Mishra, K.; Khanuja, M.; Prasad, R.; Varma, A. Biosynthesis of Zinc Oxide Nanoparticles from Azadirachta indica for Antibacterial and Photocatalytic Applications. Mater. Sci. Semicond. Process. 2015, 32, 55-61. [CrossRef]

24. Nejati, K.; Rezvani, Z.; Pakizevand, R. Synthesis of ZnO Nanoparticles and Investigation of the Ionic Template Effect on Their Size and Shape. Int. Nano Lett. 2011, 1, 75-81.

25. Mallika, A.N.; Reddy, A.R.; Reddy, K.V. Annealing Effects on the Structural and Optical Properties of ZnO Nanoparticles with PVA and CA as Chelating Agents. J. Adv. Ceram. 2015, 4, 123-129. [CrossRef]

26. Elumalai, K.; Velmurugan, S. Green Synthesis, Characterization and Antimicrobial Activities of Zinc Oxide Nanoparticles from the Leaf Extract of Azadirachta indica (L.). Appl. Surf. Sci. 2015, 345, 329-336. [CrossRef]

27. Nguyen, L.N.; Kaushik, N.; Lamichhane, P.; Mumtaz, S.; Paneru, R.; Bhartiya, P.; Kwon, J.S.; Mishra, Y.K.; Nguyen, L.Q.; Kaushik, N.K.; et al. In Situ Plasma-Assisted Synthesis of Polydopamine-Functionalized Gold Nanoparticles for Biomedical Applications. Green Chem. 2020, 22, 6588-6599. [CrossRef]

28. Gayen, R.N.; Sarkar, K.; Hussain, S.; Bhar, R.; Pal, A.K. ZnO Films Prepared by Modified Sol-Gel Technique. Indian J. Pure Appl. Phys. 2011, 49, 470-477.

29. Xiong, G.; Pal, U.; Serrano, J.G.; Ucer, K.B.; Williams, R.T. Photoluminesence and FTIR Study of ZnO Nanoparticles: The Impurity and Defect Perspective. Phys. Status Solidi C 2006, 3, 3577-3581. [CrossRef]

30. Bharathi, D.; Bhuvaneshwari, V. Synthesis of Zinc Oxide Nanoparticles (ZnO NPs) Using Pure Bioflavonoid Rutin and Their Biomedical Applications: Antibacterial, Antioxidant and Cytotoxic Activities. Res. Chem. Intermed. 2019, 45, 2065-2078. [CrossRef]

31. Vafaee, M.; Ghamsari, M.S. Preparation and Characterization of ZnO Nanoparticles by a Novel Sol-Gel Route. Mater. Lett. 2007, 61, 3265-3268. [CrossRef]

32. Suwanboon, S.; Amornpitoksuk, P.; Sukolrat, A.; Muensit, N. Optical and Photocatalytic Properties of La-Doped ZnO Nanoparticles Prepared via Precipitation and Mechanical Milling Method. Ceram. Int. 2013, 39, 2811-2819. [CrossRef]

33. Kharissova, O.V.; Dias, H.V.R.; Kharisov, B.I.; Pérez, B.O.; Pérez, V.M.J. The Greener Synthesis of Nanoparticles. Trends Biotechnol. 2013, 31, 240-248. [CrossRef]

34. Josse, J. Constitutive Inorganic Pyrophosphatase of Escherichia coli I. Purification and Catalytic Properties. J. Biol. Chem. 1966, 241, 1938-1947. [CrossRef]

35. Vaishnav, V.S.; Patel, P.D.; Patel, N.G. Indium Tin Oxide Thin Film Gas Sensors for Detection of Ethanol Vapours. Thin Solid Film. 2005, 490, 94-100. [CrossRef]

36. Bhasha, S.; Malik, P.; Santosh, S.; Purnima, J. Synthesis and Characterization of Nanocrystalline Zinc Oxide Thin Films for Ethanol Vapor Sensor. J. Nanomed. Nanotechnol. 2015, 6, 1.

37. Iqbal, Y.; Malik, A.R.; Iqbal, T.; Aziz, M.H.; Ahmed, F.; Abolaban, F.A.; Ali, S.M.; Ullah, H. Green Synthesis of ZnO and AgDoped ZnO Nanoparticles Using Azadirachta indica Leaves: Characterization and Their Potential Antibacterial, Antidiabetic, and Wound-Healing Activities. Mater. Lett. 2021, 305, 130671. [CrossRef]

38. Gas' Kov, A.M.; Rumyantseva, M.N. Nature of Gas Sensitivity in Nanocrystalline Metal Oxides. Russ. J. Appl. Chem. 2001, 74, 440-444. [CrossRef]

39. Henrich, V.E.; Cox, P.A. Fundamentals of Gas-Surface Interactions on Metal Oxides. Appl. Surf. Sci. 1993, 72, 277-284. [CrossRef]

40. Hongsith, N.; Choopun, S. Effect of Platinum Impregnation on ZnO Tetrapods for Ethanol Sensor. Adv. Mater. Res. 2008, 55, 289-292.

41. Li, C.C.; Du, Z.F.; Li, L.M.; Yu, H.C.; Wan, Q.; Wang, T.H. Surface-Depletion Controlled Gas Sensing of ZnO Nanorods Grown at Room Temperature. Appl. Phys. Lett. 2007, 91, 32101. [CrossRef]

42. Korotcenkov, G.; Brinzari, V.; Stetter, J.R.; Blinov, I.; Blaja, V. The Nature of Processes Controlling the Kinetics of Indium Oxide-Based Thin Film Gas Sensor Response. Sens. Actuators B Chem. 2007, 128, 51-63. [CrossRef]

43. Matsushima, S.; Maekawa, T.; Tamaki, J.; Miura, N.; Yamazoe, N. Role of Additives on Alcohol Sensing by Semiconductor Gas Sensor. Chem. Lett. 1989, 18, 845-848. [CrossRef]

44. Stambolova, I.; Konstantinov, K.; Vassilev, S.; Peshev, P.; Tsacheva, T. Lanthanum Doped $\mathrm{SnO}_{2}$ and ZnO Thin Films Sensitive to Ethanol and Humidity. Mater. Chem. Phys. 2000, 63, 104-108. [CrossRef]

45. Chou, S.M.; Teoh, L.G.; Lai, W.H.; Su, Y.H.; Hon, M.H. ZnO: Al Thin Film Gas Sensor for Detection of Ethanol Vapor. Sensors 2006, 6, 1420-1427. [CrossRef]

46. Kohl, D. Surface Processes in the Detection of Reducing Gases with $\mathrm{SnO}_{2}$-Based Devices. Sens. Actuators 1989, 18, 71-113. [CrossRef]

47. Barzinjy, A.A.; Azeez, H.H. Green Synthesis and Characterization of Zinc Oxide Nanoparticles Using Eucalyptus globulus Labill. Leaf Extract and Zinc Nitrate Hexahydrate Salt. SN Appl. Sci. 2020, 2, 1-14. [CrossRef]

48. Rao, T.P.; Kumar, M.C.S.; Safarulla, A.; Ganesan, V.; Barman, S.R.; Sanjeeviraja, C. Physical Properties of ZnO Thin Films Deposited at Various Substrate Temperatures Using Spray Pyrolysis. Phys. B Condens. Matter 2010, 405, $2226-2231$. 
49. Zhang, Y.L.; Yang, Y.; Zhao, J.H.; Tan, R.Q.; Cui, P.; Song, W.J. Preparation of ZnO Nanoparticles by a Surfactant-Assisted Complex Sol-Gel Method Using Zinc Nitrate. J. Sol-Gel Sci. Technol. 2009, 51, 198-203. [CrossRef]

50. Goyal, A.; Kachhwaha, S. ZnO Thin Films Preparation by Spray Pyrolysis and Electrical Characterization. Mater. Lett. 2012, 68, 354-356. [CrossRef]

51. Li, X.; Chang, Y.; Long, Y. Influence of Sn Doping on ZnO Sensing Properties for Ethanol and Acetone. Mater. Sci. Eng. C 2012, 32, 817-821. [CrossRef] 